\title{
Breve fra J. P. Junggreen
}

Ved H. V. Gregersen.

I Sønderjyske Årbøger 1937, s. 168-202, og 1938, s. 111-1j1 og 306-323, har højskoleforstander Hans Lund udgivet en række af J. P. Junggreens breve. I indledningsordene til denne brevsamling udtrykkes håbet om, at endnu flere af J. P. Junggreens breve må blive gjort tilgængelige for den historisk interesserede læserkreds, og dette håb kan nu opfyldes med hensyn til de breve, som J. P. Junggreen har sendt til Peder Skau, Bukshave. ${ }^{1}$

Forholdet mellem J. P. Junggreen og Peder Skau var venskabeligt. Ikke alene stod de begge i forreste række i kampen for Sønderjyllands danskhed $i$ årene efter 1864, men de forenedes også i fælles kritik af Hans A. Krügers politiske linję og i en frontstilling imod tidens "ultragrundtvigianske venstremænd $₫$.

Der er dog først fra 1880 bevaret breve fra J. P. Junggreen til Peder Skau, og det første bevarede er Junggreens kendte opfordring af 21. sept. 1880 til en række af sine samtidige fremtrædende dansksindede medborgere vedrørende sudbredelsen af god dansk læsning i Nordslesvig ". Dette brev er imidlertid trykt et par gange tidligere ${ }^{4}$ og skal derfor forbigås her, hvorimod de følgende breve fra årene 1880 til 1884 har nyhedens interesse.

Aabenraa, 27. October 80.

Kjære Ven!

Du har fuldstændig Ret $i$, at det er paa Tide, vi give et Livstegn fra os, og jeg vilde allerede have sammenkaldt Bestyrelsen, naar ikke følgende Omstændighed havde bevæget mig til at opsætte det.

Dagen efter, at vi havde stiftet Foreningen, ${ }^{5}$ reiste jeg til Kjøbenhavn, og da jeg en Gang var der, forekom det mig rigtigst strax at gjøre Skridt for at faa nogen Understottelse derovrefra. Jeg talte derfor med Ploug ${ }^{6}$ og Kayser, ${ }^{7}$ og de foranstaltede om 
Fredagen et Møde af nogle faa af Kbnhvns Rigmænd, for med dem at overlægge, paa hvad Maade en Sum Penge bedst lod sig tilveiebringe. I dette Møde dellog jeg og udviklede for de Tilstedeværende, hvor nødvendigt det var, at der gjordes noget mere end hidtil for at opretholde Sagen, der var et Livsspørgsmaal, ikke blot for os, men ligesaa meget for det danske Folk. - De syntes ogsaa meget villige til at gjøre noget for os, og det besluttedes, at de om Onsdagen (idag for 8 Dage) vilde sammenkalde et Møde af et Halvthundrede af Kjøbenhavns formuende og patriotiske Mrend og bede dem tilveiebringe circa $5000 \mathrm{Kr}$. aarligt, hvilken Sum jeg havde forlangt af dem. Jeg skrev i denne Anledning om Løverdagen et Brev til Ploug, som han skulde oplase for denne Forsamling, og bad ham tillige deri om snarest muligt at underrette mig om, hvad Resultatet var bleven. Paa dette Brev har jeg ventet fra Dag til Dag, da vi jo meget bedre vilde kunne lægge vor Plan, naar vi vidste, at vi raadede over en saadan Sum. - Du seer saaledes, at jeg ikke har været ledig, men — jeg har endnu intet hørt, og vil nu vente til Søndag. Har jeg saa ingen Brev faaet, vil jeg sammenkalde Bestyrelsen til hen $i$ næste Uge.

Ja, tilvisse var det en Feil, at Mødet ikke var anmeldt, men det er udelukkende Bekkers ${ }^{8}$ Skyld, der blev ved at fraraade det og at paastaa, at det ikke behøvedes. Nu komme vi rimeligvis til at betale en Del Mulcter, hvilke Penge kunde have været bedre anvendt.

Det er sørgeligt med de Haderslevs Folk, at de dog ikke kunne forliges. ${ }^{9}$ Med vor Kredsdag er det galt nok, dog troer jeg ikke, der er Fare for, at der skal blive valgt en tysk Landdagsmand. Det er den sydligste Del af Kredsen omkring ved Graasteen og Flensborg Fjord, der er bleven saa utrolig sløv og ussel. Der var heller ingen mødt derfra til Mødet, og i disse Egne vil der blive noget at gjore for os, thi - det er jo ikke de Sunde, der have Lægen behov, men de, som lide ilde. Dog vil jeg aldrig give mit Samtykke til, at vi anvende vore Midler syd for Flensborg Fjord. Det anseer jeg for det samme som at kaste dem bort. ${ }^{10}$

$\mathrm{Nu}$ lev vel, kjaere Ven. Undskyld min daarlige Skrift. Jeg har meget travlt idag, men syntes, Du skulde have Svar strax.

Din hengivne

J. P. Junggreen. 


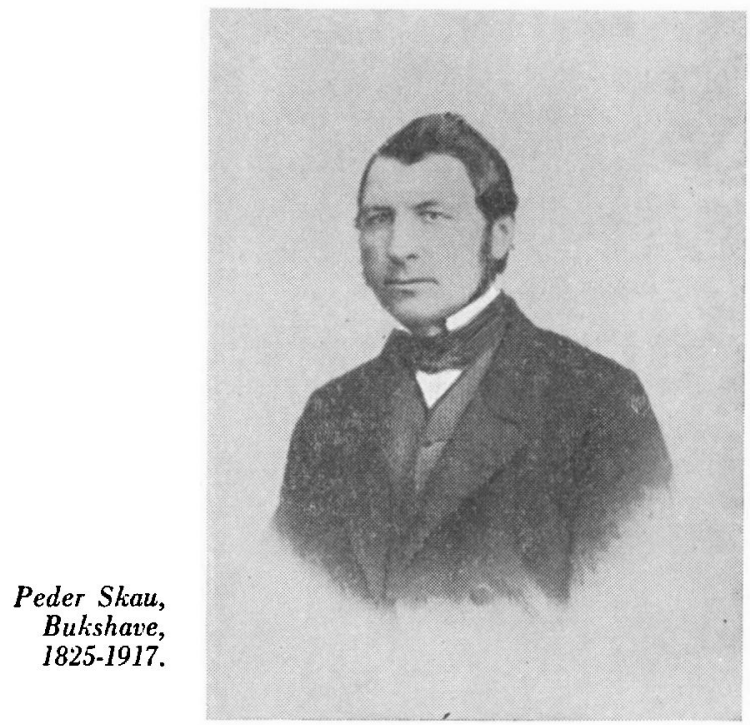

Kjære Ven!

Aabenraa, 31. October 1880.

Mine Bestræbelser i Kjøbenhavn have baaret god Frugt. Der blev ved Mødet strax tegnet $2000 \mathrm{Kr}$. aarligt i 5 Aar, og Ploug haaber at bringe det op til 4 à 5000 . Dermed kan der saa nok gjøres noget. ${ }^{11}$

Maa jeg nu bede Dig møde her hos mig idag 8 Dage, Søndagen den 7. Novbr. Kl. 1.

Jeg har tænkt, at vi skulde tale om:

1. Udstedelsen af en offentlig Opfordring til at indtræde i For. eningen.

2. Udnævnelsen af Kredsformænd, til hvem Indmeldelse kan finde Sted. Dette Punkt er jo noget vanskeligt, da Navnene maa offentliggjøres, og vi jo næppe kunde indlade os paa at indhente vedkommendes Samtykke skriftligt. Men vi maa have dem, da vi ellers ikke kunde vente nogen betydelig Tilgang af Medlemmer.

3. maa vi tale om den Maade, hvorpaa vi ville søge at virkeliggjøre den Opgave, vi have stillet os. Hovedsagelig ville vi jo vistnok komme til at virke ved Oprettelsen af smaa Bibliotheker. Jeg seer, at Polakkerne ere komne paa den samme Tanke. - 
Jeg har naturligvis ogsaa skrevet til Madvig, og I følges vel ad herover.

Skulde Du komme til Christiansfeld, sua bed Rebslager Oster, ${ }^{19}$ om vi maa nævne ham iblandt Kredsformændene. Jeg havde indbudt ham til Mødet, men han kunde ikke komme, hvorimod han skrev mig et langt og meget godt og fornuftigt Brev, som Du kan takke ham for fra mig, og sige ham, at jeg nok engang skal besvare. Jeg har havt en stor Deel Skriveri at gjøre i den senere Tid.

$\mathrm{Nu}$ haaber jeg at see Dig næste Søndag og forbliver med den venligste Hilsen

\section{Din hengivne}

J. P. Junggreen.

Kjære Ven!

Aabenraa, 29. Septbr. 1881.

Tak for Dit venlige Brev. Du seer, at jeg nu har hugget Knuden over. Jeg kunde ikke handle anderledes, thi det synes jo ikke, at Hans Lassen har noget meget levende Ønske om at afgive den omtalte Erklaering; ${ }^{18}$ ellers var den vel kommet for, og skulde jeg maaskee efter lang Uvished tilsidst have modtaget den som en Gunstbevisning, saa vilde dette i Forbindelse med det fanatiske Had, som de Herrer Grundtvigianere synes at nære til mig, have gjort den i Forveien vanskelige Stilling son Rigsdagsmand i den Grad ubehagelig, at jeg ikke vil overtage den. - Dertil kommer, at jeg jo havde været nødt til at fortsætte den $\mathbf{i}$ "Dannevirke" paabegyndte bittre Polemik, thi lade mig hundse paa den Maade, som det skeete af de Herrer Poulsen \& Consorter, ${ }^{14}$ kunde jeg dog ikke. - Jeg hører, at Herr Poulsen er bleven gjort til Præst i den senere Tid; han burde hellere være bleven Jesuit; med hans Færdighed $i$ ved smaa Tilsnigelser og Udeladelser at forvanske Sandheden vilde han vist kunne have bragt det til noget, naar han var gaaet den Vei.

Gid I nu kunde enes om en Kandidat i Eders Kreds. For os kan der jo ikke være stort at indvende imod Hans Lassen, om jeg end villig indrømmer, at han besidder de af Dig paapegede Mangler for at kunne repræsentere os paa den rette Maade i Rigsdagen. Derimod antager jeg, at det maa være et surt Eble at bide $i$ for de Herrer Appel, Lykke, Rasmus Hansen etc., ${ }^{15}$ naar de skulle til 


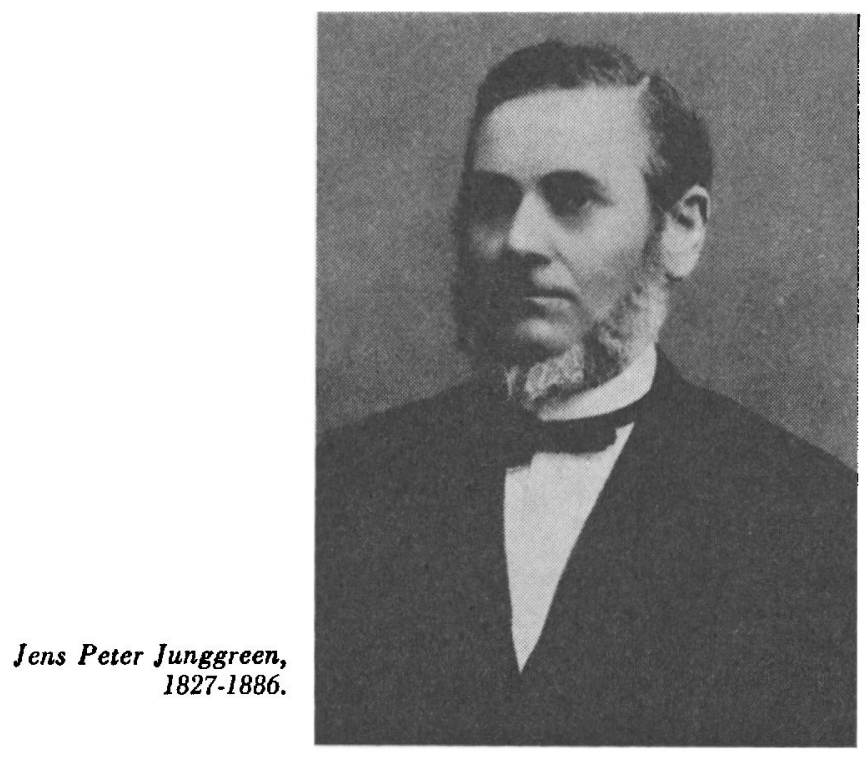

at stemme paa ham. Men det faa de nu ordne, som de kunne. Med en saa fuldstændig Mangel paa Villie til for det almenes Skyld at underordne sig, som disse Herrer have vist, ere de en Ulykke for vort Land og vor Sag, som de tilsidst ville ødelregge. Først havde vi alle Valgmændene samlede, og der kom de i Minoritet, saa fik de Afgjørelsen af Sagen lagt i Hænderne paa Valgmændene for 1ste Kreds, og der gik det dem ligesaa, og derefter havde de tiltrods for alle de snuuke Fraser $i$ deres Indbydelse intet bedre at gjøre end at reise Landet rundt for at forhindre, at Folk fandt sig i den Afgjorelse, der paa denne Maade var bleven truffet, og som jeg er overbevist om, at den store Befolkning med Glæde vilde have fundet sig i. - Sorg nu ikke, fordi dette er kommet saaledes, kjæere Ven! Du kan være overbevist om, at den, der i dette Øieblik renoncerer, tjener Sagen bedre end den, der gaaer den modsatte Vei, og dette skal ogsaa nok med Tiden gaa op for Folket. Du og jeg ere jo for Øieblikket faldne som Offre for en Klike. Lad dem nu selv styre Tingene, som de kunne. Vi have en fuldstændig reen Samvittighed i denne Sag.

Din hengivne og forbundne

$J$. P. Junggreen. 


\section{Kjære Skau!}

Aabenraa, 7. Febr. 1884.

Jeg er fra flere Sider bleven anmodet om at foranstalte en Sammenkomst af et mindre Antal gode danske Mænd for at tage under Overveielse, om der ikke fra Befolkningens Side kunde og burde gjøres noget i Anledning af de usle og fortrykte Kaar, under hvilke vort Modersmaal er stillet, i Skolen, under Retspleien og i alle andre of fentlige Forhold.

Idet jeg efterkommer denne Anmodning, indbyder jeg Dig herved til et Møde her i Aabenraa i Hotel Danmark Onsdagen den 13. Febr. Formiddag Kl. 10.

Mødet bliver fuldstændig privat, og der udstedes kun 25 Indbydelser. $^{16}$

Din hengivne

J. P. Junggreen.

\section{Kjære Ven!}

Aabenraa, 29. Juli 1884.

Det gjør mig lidt ondt, at Du ikke rigtig vil med. Det har naturligvis ikke været min Tanke, at vi skulde holde Foredrag af samme Slags; jeg troede tvertimod, at vi havde været godt skikket til at supplere hinanden. Enhver Fugl synger jo med sit Næb, og mine Foredrag vilde blive af den Slags, jeg $i$ den senere Tid har holdt herhjemme, medens det forekom mig, at Du maatte kunne fortælle meget om den Kamp for vor Sag, der er ført af vore Formænd. Du har jo mange Minder fra hin Tid, maa jo have hørt meget af Din Broder $^{17}$ og har jo ogsaa selv en rig Erfaring. Om alt dette er der jo nok at faa at læse, men jeg har $i$ den senere Tid gjort den Erfaring, at det "levende Ord " griber og virker paa Menneskene $i$ en ganske anden Grad mere umiddelbart end det skrevne, og at meget af det, ingen bryder sig om, naar de læse det, dog gjør Indtryk paa dem, naar de høre det af en Mands Mund. Derfor mente jeg, at vi skulde drage ud for at tale til vore Landsmænd, belærende, opmuntrende, alt efter enhvers forskjællige Begavelse. - Det blev jo ogsaa mindre uoverkommeligt, naar man delte Arbeidet. Nu, kjæere Skau, gjør, hvad Du troer at kunne overkomme. At Du vil holde Foredrag i Jylland, er ogsaa 
meget gavnligt. Baade der og her gjalder det om at holde Stemningen oppe - mest dog her. Jeg vil nu offentlig tilbyde at holde nogle.Foredrag og henstiller til Dig, om Du dog ikke vil gjøre det samme. Hvis ikke, da lad idetmindste Folk underhaanden faa at vide, at $\mathrm{Du}$ vil det. Jeg troer ogsaa, at det paa anden Maade vil være godt for Sagen, om vi selv tage dette i vor Haand. Vor Sag kan kun have Gavn af, at vi vise vore Modstandere, at vi kunne det. De ville jo saa gjerne see ned paa os. - Tænk nu derpaa, kjære Ven. Jeg vilde saa gjerne, at netop $D u$ skulde tage Deel i dette Arbeide.

\section{Din hengivne}

J. P. Junggreen.

\section{NOTER}

1. Peder Skaus arkiv, LA.

2. Brev fra Peder Skau til Carl Ploug 1879 7/11: "Ofte maa inan imidlertid tage sin Overbevisning fangen i den Sag, vi kæmpe herovre. Saaledes har vi i Dag atter gjenvalgt Krüger til Medlem af Deputeretkammeret, skjøndt alle vi Østboere helst vilde have valgt J. P. Junggreen. Men Vesteramterne see jo en Halvgud i K[rüger], og vi vilde hellere underkaste os end, at der skulde komme en Spaltning iblandt os. Formodentlig naaer han aldrig at komme derned, ligesom han jo holder fast ved sit Standpunct i Edsspørgsmaalet «.

3. SJy Årb 1938, s. 148 (brev fra J. P. Junggreen til Villars Lunn).

4. Sprogforeningens Årsberetning 1929-30, s. 7-8; SJy Årb 1938, s. 112, hvor dateringen beklageligvis er foretaget med forkert årstal (1879 i stedet for 1880$)$.

5. På et møde den 10. oktober 1880 dannedes Forening til det danske Sprogs Bevarelse i Nordslesvig (Sprogforeningen).

6. Journalisten og forfatteren, redaktør Carl Ploug, se iøvrigt DBL.

7. Tomrermester H. H. Kayser, formand for foreningen "Dannebrog", se iøvrigt DBL.

8. Carl Bekker, advokat, i sonderjysk politik tilhænger af edsaflæggerstandpunktet, efter Junggreens død i 1886 formand for Sprogforeningen, se iøvrigt DBL.

9. Der tænkes formodentlig på striden mellem edsnægtere og edsaflæggere.

10. Denne udtalelse fra 1880 er interessant for bedømmelsen af afstemningstidens såkaldte Åbenrå-standpunkt.

11. Jvf. SJy Årb 1938, s. 113 (brev fra J. P. Junggreen til P. Madvig).

12. Rebslager Øster i Christiansfeld havde i 1866 været medlem af den deputation, der i 1866 overbragte en adresse til Wilhelm I af Preussen, se SJy Årb 1894, s. 157-160. 
13. Ved Krügers død den 27. aug. 1881 var man ikke nảet til enighed om, hvem der skulle være hans efterfølger som rigsdagsmand. Den 17. sept. havde der været et valgmandsmode $\mathrm{i}$ Vojens, hvor 92 havde stemt på Junggreen og 22 på Hans Lassen, men den 20. sept. fik Hans Lassen 55 stemmer på et lignende møde i Sønderborg, mens Junggreen måtte nøjes med 13. Den 28. sept. erklærede Junggreen da, at han ikke ville tage imod valg. Af et Parti af mine Landsmænd vil jeg ikke vælges .

14. Frimenighedspræst L. B. Poulsen havde bl. a. udtalt, at *Junggreens Færd med $H$. Krüger paa det sidste har været os en Forargelse, thi det er jo vitterligt, at Krïger paa det sidste viste ham bort «, se iøvrigt SJy Arb 1938, s. 136 (brev fra J. P. Junggreen til Gustav Johannsen).

15. Alle grundtvigianere og tilhængere af edsnægter-standpunktet. Da Hans Lassen aflagde eden på den tyske forfatning, vakte dette en voldsom kritik af ham, især fra edsnægternes hârde kerne i Haderslev vesteramt.

16. Resultatet af mødet blev en adresse til det preussiske kultusministerium med anmodning om ophævelse af instruksen af 9. marts 1878 og anordning af en omhyggelig undervisning $i$ dansk.

17. Laurids Skau. 